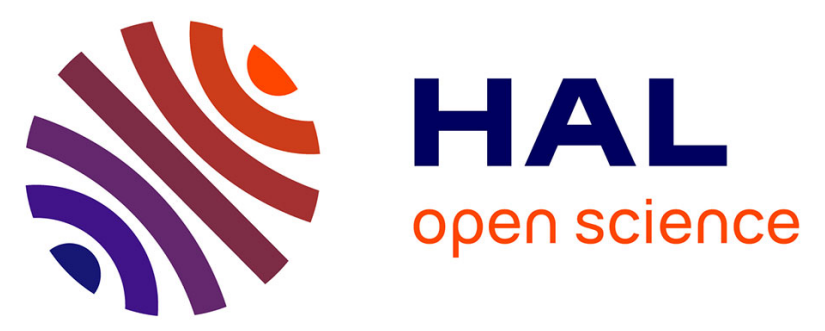

\title{
Electroactive mixed self-assembled monolayers: Lateral interactions model updated to interactions between redox and non-redox species
}

Olivier Alévêque, Eric Levillain

\section{- To cite this version:}

Olivier Alévêque, Eric Levillain. Electroactive mixed self-assembled monolayers: Lateral interactions model updated to interactions between redox and non-redox species. Electrochemistry Communications, 2013, 34, pp.165-169. 10.1016/j.elecom.2013.06.009 . hal-03344569

\section{HAL Id: hal-03344569 \\ https://univ-angers.hal.science/hal-03344569}

Submitted on 15 Sep 2021

HAL is a multi-disciplinary open access archive for the deposit and dissemination of scientific research documents, whether they are published or not. The documents may come from teaching and research institutions in France or abroad, or from public or private research centers.
L'archive ouverte pluridisciplinaire $\mathbf{H A L}$, est destinée au dépôt et à la diffusion de documents scientifiques de niveau recherche, publiés ou non, émanant des établissements d'enseignement et de recherche français ou étrangers, des laboratoires publics ou privés. 
Provided for non-commercial research and education use. Not for reproduction, distribution or commercial use.

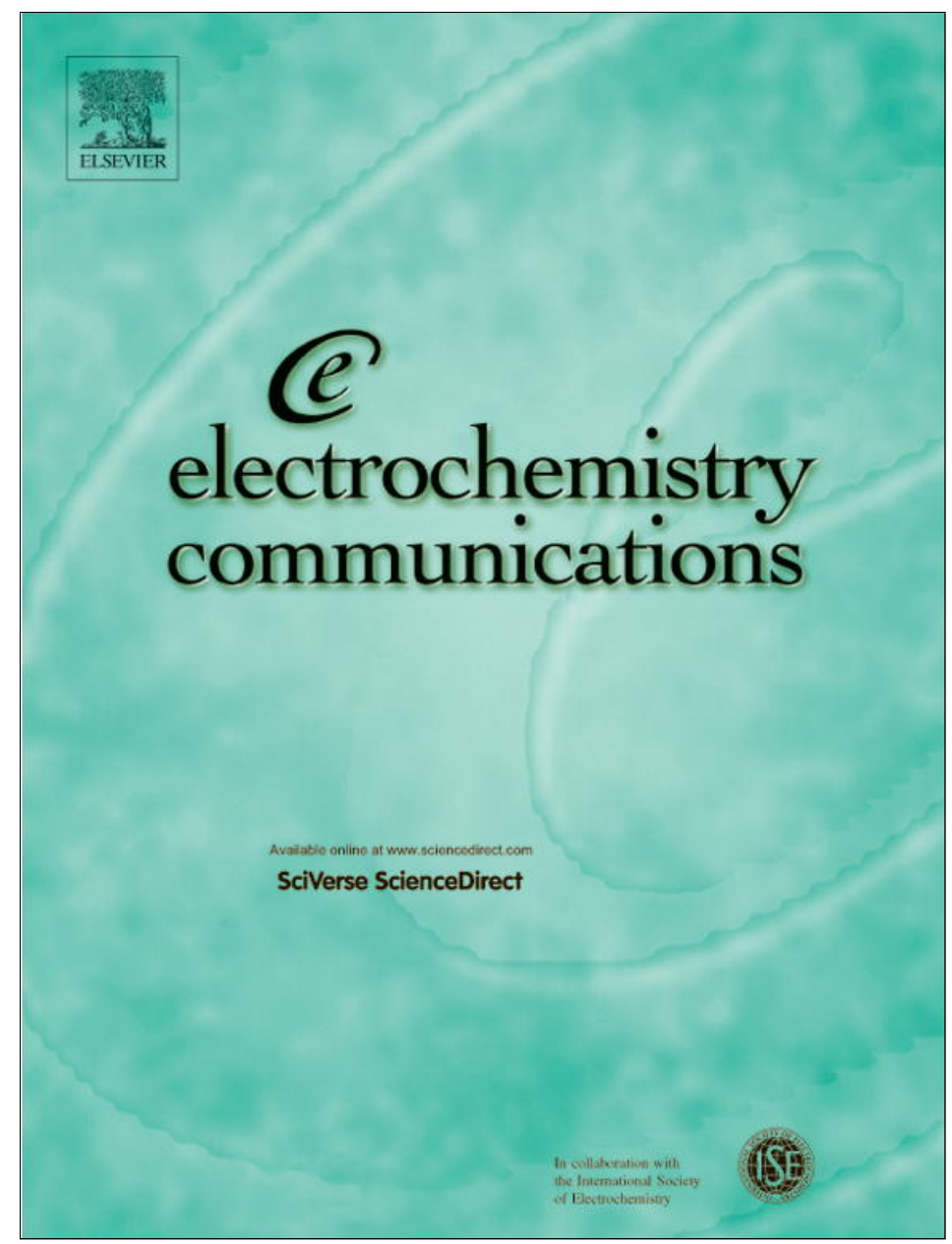

This article appeared in a journal published by Elsevier. The attached copy is furnished to the author for internal non-commercial research and education use, including for instruction at the authors institution and sharing with colleagues.

Other uses, including reproduction and distribution, or selling or licensing copies, or posting to personal, institutional or third party websites are prohibited.

In most cases authors are permitted to post their version of the article (e.g. in Word or Tex form) to their personal website or institutional repository. Authors requiring further information regarding Elsevier's archiving and manuscript policies are encouraged to visit:

http://www.elsevier.com/authorsrights 


\title{
Electroactive mixed self-assembled monolayers: Lateral interactions model updated to interactions between redox and non-redox species
}

\author{
Olivier Alévêque *, Eric Levillain \\ L'UNAM Université, Université d'Angers, CNRS UMR 6200, Laboratoire MOLTECH-Anjou, 2 bd Lavoisier, 49045 Angers cedex, France
}

\section{A R T I C L E I N F O}

\section{Article history:}

Received 10 May 2013

Received in revised form 4 June 2013

Accepted 11 June 2013

Available online 15 June 2013

\section{Keywords:}

Self-assembled monolayers

Cyclic voltammetry

Lateral interactions

Redox interactions

Non-redox interactions

\begin{abstract}
A B S T R A C T
The lateral interactions model, dedicated to random and non-random distributed electroactive species on redox responsive self-assembled monolayers (SAM), was extended to interactions between redox and non-redox species. This approach supports an unusual result achieved in the field of electrochemical transduction without covalent links between redox and complexant units in mixed SAM.
\end{abstract}

(C) 2013 Elsevier B.V. All rights reserved.

\section{Introduction}

Since their discovery in 1983 [1], self-assembled monolayers have become an ideal system for the theoretical study of interfacial phenomena [2], especially in the field of electrochemistry.

In a previous work [3], we have presented a theoretical study to complete the lateral interaction model proposed by E. Laviron [4], by extending this initial model to non-random distributions of electroactive sites adsorbed on surface. This model enables current-voltage behaviours to be simulated and allows extracting characteristics parameters $\left(E_{p}, i_{p}\right.$ and FWHM) of cyclic voltamograms (CVs) obtained from any surface distribution of electroactive self-assembledmonolayer(SAM).

Herein, we propose to update the lateral interaction model when interactions between redox and non-redox species are taking into account. Based on the same empirical numerical approach previously used, characteristic parameters $\left(\mathrm{E}_{\mathrm{p}}, \mathrm{i}_{\mathrm{p}}\right.$ and $\left.\mathrm{FWHM}\right)$ of cyclic voltamograms (CVs) are extracted and discussed. In addition, this work supports an unusual result achieved in the field of electrochemical transduction without covalent links between redox and complexant units in electroactive mixed SAM [5].

\footnotetext{
* Corresponding author. Tel.: +33 241735090; fax: + 33241735405. E-mail address: olivier.aleveque@univ-angers.fr (O. Alévêque).
}

\section{Generalized lateral interactions model}

To summarize previous works, the generalized lateral interactions model can be defined according to the main following hypotheses [3,4,6,7]:

- The electroactive centers are distributed on substrate with a unimodal statistical distribution of electroactive neighbours. A parameter $\phi(\theta)$, between 0 and 1 , defined for a normalized surface coverage $\theta$, quantifies the segregation level of the electroactive centers. For a randomly distributed SAM, $\phi(\theta)=\theta$, and when a segregation exist on the surface, $\phi(\theta)>\theta$.

- The sum of normalized surface coverage $\theta_{\mathrm{O}}$ and $\theta_{\mathrm{R}}$ of oxidized (O) and reduced $(\mathrm{R})$ species is constant and equal to $\theta$,

- The surface occupied by one molecule of $O$ is equal to the surface occupied by one molecule of $\mathrm{R}$,

- The electrochemical rate constant $k_{s}$ is independent of the coverage,

- $\mathrm{a}_{\mathrm{OO}}, \mathrm{a}_{\mathrm{RR}}$ and $\mathrm{a}_{\mathrm{OR}}$ are the interaction constants between molecules of $O$, molecules of $R$ and molecules of $O$ and $R$, respectively. $a_{i j}$ is positive for an attraction and negative for a repulsion. The $a_{i j}$ values are assumed to be independent of the potential and distribution.

For a full reversible reaction $\left(\mathrm{k}_{\mathrm{s}} \rightarrow \infty\right)$, cyclic voltammograms are totally reversible, and the characteristic parameters as full width at half maximum (FWHM), peak potential $\left(E_{p}\right)$ and peak current $\left(i_{p}\right)$ ) are defined as:

$E_{p}(\phi(\theta))=E_{0}^{\prime}+\frac{R T}{n F} S \phi(\theta)$ 
$i_{p}(\phi(\theta), \theta)=\frac{n^{2} F^{2} v A \Gamma_{m}}{R T} \frac{\theta}{2(2-G \phi(\theta))}$

$\operatorname{FWHM}(\phi(\theta)) \stackrel{|G \phi(\theta)<1|}{\approx} \frac{R T}{n F}\left(2 \ln (2 \sqrt{2}+3)-\frac{3 \sqrt{2}}{2} G \phi(\theta)\right)$

with, $G=a_{O O}+a_{R R}-2 a_{O R}$ et $S=a_{R R}-a_{O O} \quad(|G|$ and $|S| \leq 2)$
In this model, the interactions with non-electroactive species are not taken into account, because this model was created to perfectly fit with mixed SAMs where the diluent used does not interact with electroactive species. The typical example is the case of electroactive mixed SAMs diluted with alkanethiols.

Based on this fact, the purpose of this work is to introduce, in the model, interactions with the non-electroactive species (D) and to show if these interactions can influence the the i-E characteristics or not. Note that only one type of diluent is used in this study. $\theta=0.25 / \theta_{D}=0.75$
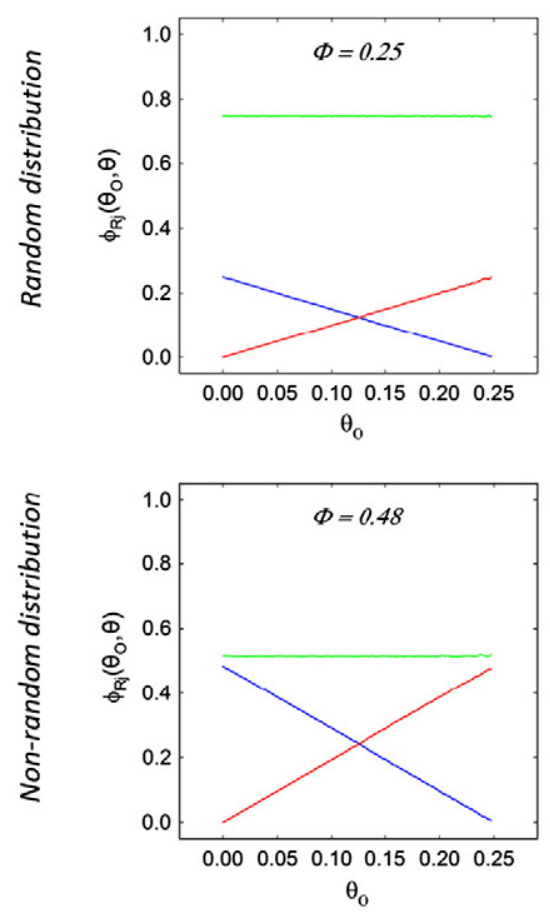

$\theta=0.25 / \theta_{D}=0.75$
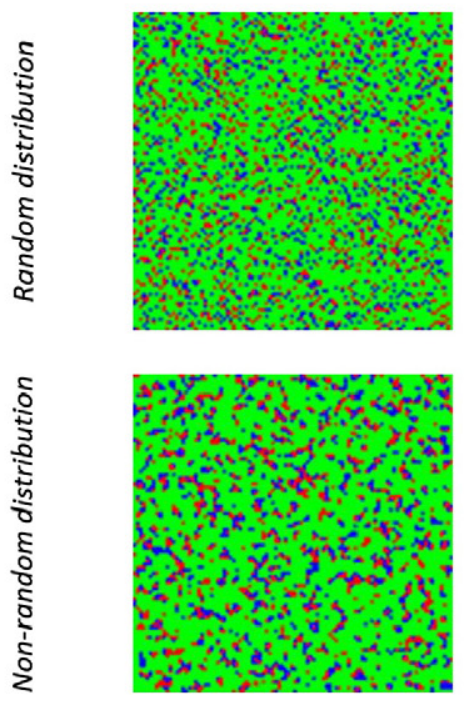

$\theta=0.40 / \theta_{D}=0.60$
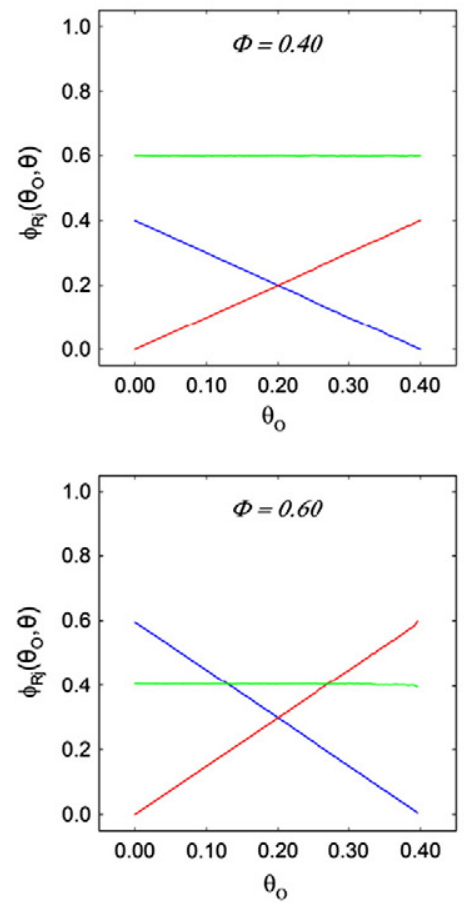

$\theta=0.40 / \theta_{D}=0.60$
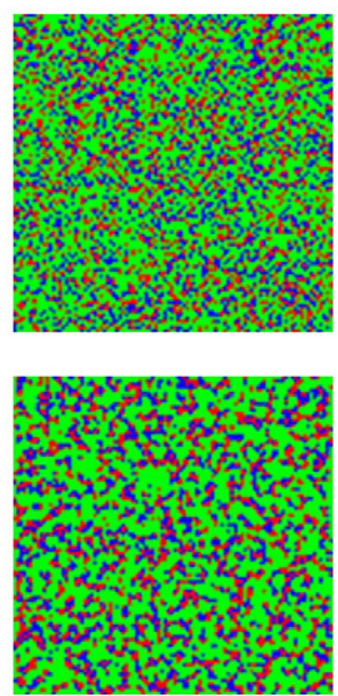

$\theta=0.75 / \theta_{D}=0.25$
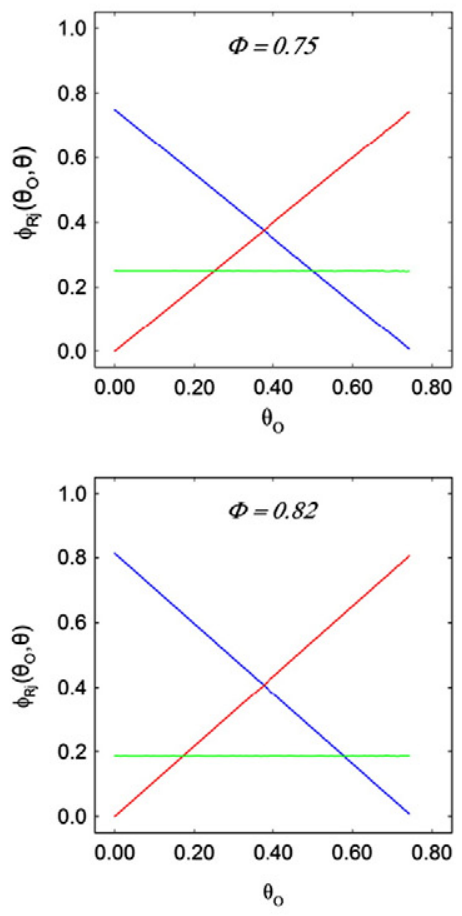

$\theta=0.75 / \theta_{D}=0.25$
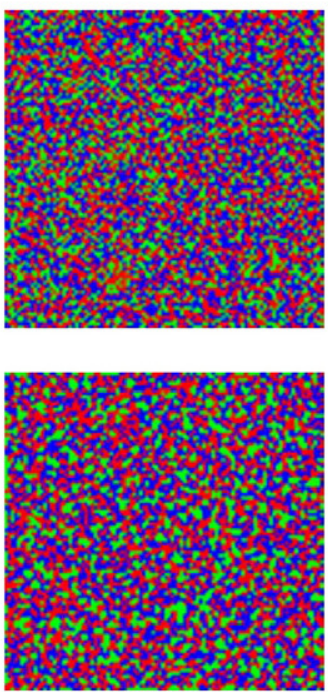

Fig. 1. (Top) Dimensionless quantities $\phi_{R R}\left(\theta_{O}, \theta\right)$ (blue), $\phi_{R O}\left(\theta_{O}, \theta\right)$ (red) and $\phi_{R D}\left(\theta_{O}, \theta\right)$ (green) vs. $\theta_{O} \in[0, \theta]$ for three various $\theta(0.25,0.4$ and 0.75$)$ and two different surface distributions. (Bottom) Binary images obtained from calculated matrices during an oxidation step for $\theta_{\mathrm{O}} / \theta=50 \%$ (intersection of the blue and red lines) and used for the calculation of dimensionless variables quantities $\phi_{i j}\left(\theta_{0}, \theta\right)$. For each matrix, R species are represented in blue, 0 species are represented in red and D species are represented in green. The size of the matrices is $(100 \times 100)$. 


\section{Experimental}

\subsection{Numerical models}

All procedures to model SAMs with matrix were clearly described in previous papers [8].

Essentially, the mixed SAMs with different molecular surface distributions (i.e. different $\phi(\theta)$ - Fig. 1), were numerically modeled $(C++)$ by a square matrix $\mathrm{M}(\mathrm{X}, \mathrm{Y})$ composed of "1" (site occupied by an electroactive specie initially in its reduced form) and of "0" (site occupied by a non electroactive specie, i.e. the diluent). The relation between the number of " 1 " and the "total number of sites" experimentally corresponds to the normalized surface coverage of electroactive species $\theta \in[0,1]$. Similarly, the relation between the number of " 0 " and the "total number of sites" experimentally corresponds to the normalized surface coverage of non-electroactive species $\theta_{D} \in[0,1]$. The relation, $\theta+\theta_{\mathrm{D}}=1$, is always true.

The oxidation process $\left(R_{a d s} \rightleftarrows O_{a d s}+n e^{-}\right)$is simulated by the random replacement of reduced species "1" by oxidized species "2". At each step of the oxidation process, the relation $\theta_{\mathrm{O}}+\theta_{\mathrm{R}}=\theta$ is always verified.

\subsection{Interactions calculation during the numerical oxidation}

At each step of the replacement (i.e. for various $\theta_{0}$ ), we calculated interactions between all species by means of 9 dimensionless quantities:

- Interactions with $R: \phi_{R R}\left(\theta_{0}, \theta\right), \phi_{R O}\left(\theta_{0}, \theta\right), \phi_{R D}\left(\theta_{0}, \theta\right)$,

- Interactions with $0: \phi_{O R}\left(\theta_{O}, \theta\right), \phi_{O O}\left(\theta_{O}, \theta\right), \phi_{O D}\left(\theta_{O}, \theta\right)$

- Interactions with $D: \phi_{D R}\left(\theta_{0}, \theta\right), \phi_{D O}\left(\theta_{0}, \theta\right), \phi_{D D}\left(\theta_{0}, \theta\right)$.

$\phi_{i j}\left(\theta_{O}, \theta\right)$, is representative of the average number of interactions between species $\mathrm{i}(\mathrm{O}, \mathrm{R}$ or $\mathrm{D})$ and species $\mathrm{j}(\mathrm{O}, \mathrm{R}$ or $\mathrm{D})$ per species $\mathrm{i}$.

Taking into account only the nearest neighbours interactions, $\phi_{i j}\left(\theta_{O}, \theta\right)$ can be expressed by:

$\phi_{i j}\left(\theta_{0}, \theta\right)=\frac{1}{N_{\max , \theta=1}} \times \frac{\sum_{X}^{X} \sum_{y}^{Y} \sum_{M_{\theta_{0}, \theta}(x, y)=i} M_{\theta_{0}, \theta}(x, y) N_{j}(x, y)}{\sum_{X}^{X} \sum_{y}^{Y} \sum_{M_{\theta_{0}, \theta}(x, y)=i} M_{\theta_{0}, \theta}(x, y)} \in[0,1]$

$\left(M_{\theta_{0}, \theta}(x, y):\right.$ Matrix generated for given surface coverages $\theta_{0}$ and $\theta$ with $N_{j}(x, y)$ : Number of direct neighbours $j$ close to $M(x, y)$.

$N_{\max , \theta=1}:$ Maximum number of direct neighbours. 6 in the case of hexagonal packing.

\section{Results and discussion}

\subsection{Numerical results}

Fig. 1 shows the trend of the three dimensionless quantities corresponding to interactions with $\mathrm{R}$ when $\theta$ and $\phi(\theta)$ are modulated. As previously observed [3], $\phi_{R R}\left(\theta_{O}, \theta\right)$ and $\phi_{R O}\left(\theta_{O}, \theta\right)$ exhibited a linear dependence with $\theta$ and $\phi(\theta)$. The parameter $\phi_{R D}\left(\theta_{0}, \theta\right)$ is constant during the oxidation process and is only dependant of the segregation factor $\phi(\theta)$. This means that, the number of species D around each electroactive specie remains constant, just because $D$ is not affected by the oxidation process.

To generalize, numerical simulations lead to:

$$
\begin{aligned}
& \phi_{i j}\left(\theta_{0}, \theta\right)=\frac{\phi(\theta)}{\theta} \theta_{j} \quad \text { with }(i, j)=(0 \text { or } R) \\
& \text { and } \\
& \phi_{i D}\left(\theta_{O}, \theta\right)=1-\phi(\theta) \quad \text { with }(i)=(0 \text { or } R)
\end{aligned}
$$

\subsection{Modification of Laviron's interaction model}

\subsubsection{Surface activities}

The theories of Laviron and Frumkin [9-12], using the mean field theory, suggest that the surface activities of the oxidized and reduced species are not exactly equal their surface concentrations but are modulated by an exponential term containing interaction constants:

$\gamma_{i}=\Gamma_{i} \exp \left[\sum_{k}-2 a_{i k} \theta_{k}\right] \quad$ with $i, k=0$ and $R$

Using the methodology applied in previous papers [3], the surface activities of the oxidized, reduced and non-redox species can be expressed with the term $\phi_{i k}\left(\theta_{0}, \theta\right)$, i.e. in function of lateral interactions between species. Eq. (6) can be formulated as following:

$\gamma_{i}=\Gamma_{i} \exp \left[\sum_{k}-2 a_{i k} \phi_{i k}\left(\theta_{0}, \theta\right)\right] \quad$ with $i, k=O, R$ and $D$

With Eqs. (5) and (7), the surface activity of the two states of the redox specie is given by:

$\left\{\begin{array}{l}\gamma_{O}=\Gamma_{O} \exp \left[-2 a_{O O} \frac{\phi(\theta)}{\theta} \theta_{O}-2 a_{O R} \frac{\phi(\theta)}{\theta} \theta_{R}-2 a_{O D}(1-\phi(\theta))\right] \\ \gamma_{R}=\Gamma_{R} \exp \left[-2 a_{R R} \frac{\phi(\theta)}{\theta} \theta_{R}-2 a_{R O} \frac{\phi(\theta)}{\theta} \theta_{O}-2 a_{R D}(1-\phi(\theta))\right]\end{array}\right.$

Using the same formalism, $\mathrm{a}_{\mathrm{OD}}$ is the interaction constant between oxidized and diluent molecules. $\mathrm{a}_{\mathrm{RD}}$ is the interaction constant between reduced and diluent molecules.

\subsubsection{Cyclic voltammetry parameters for a reversible system}

The i-E characteristic (IUPAC convention) can be expressed:

$$
\begin{aligned}
i(t) & =n F A k_{s}\left(\gamma_{O} \exp \left[-\alpha \frac{n F}{R T}\left(E-E^{0^{\prime}}\right)\right]-\gamma_{R} \exp \left[(1-\alpha) \frac{n F}{R T}\left(E-E^{0^{\prime}}\right)\right]\right) \\
& =n F A k_{S}\left(\gamma_{O} \eta^{-\alpha}-\gamma_{R}{ }^{1-\alpha}\right) \text { with } \eta=\exp \left[\frac{n F}{R T}\left(E-E^{0^{\prime}}\right)\right] \text { and } E^{0^{\prime}} \\
& =E^{0}+\frac{R T}{n F} \ln \left(\frac{b_{R}}{b_{0}}\right) \text { with } b_{R} \text { and } b_{O} \text { the adsorption coefficients }
\end{aligned}
$$

Using surface activity of the two redox states, Eq. (10), we reach:

$$
\left\{\begin{array}{l}
i(t)=n F A k_{S} \Gamma_{\max }\left(\begin{array}{l}
\theta_{O}(t) \eta^{-\alpha} \exp \left[-2 a_{O O} \frac{\phi(\theta)}{\theta} \theta_{O}-2 a_{O R} \frac{\phi(\theta)}{\theta} \theta_{R}-2 a_{O D}(1-\phi(\theta))\right] \\
-\theta_{R}(t) \eta^{1-\alpha} \exp \left[-2 a_{R R} \frac{\phi(\theta)}{\theta} \theta_{R}-2 a_{R O} \frac{\phi(\theta)}{\theta} \theta_{O}-2 a_{R D}(1-\phi(\theta))\right]
\end{array}\right)(10) \\
i(t)=n F A \frac{d \Gamma_{O}}{d t}=n F A \Gamma_{\max } \frac{d \theta_{O}}{d t} \\
\text { with } n, F, A, k_{S}, R, T, E, E_{0}^{\prime} \text { and } t \text { have their usual meanings }
\end{array}\right.
$$

For a fast reversible system $\left(k_{s} \rightarrow \infty\right)$, the Nernst equation is applicable:

$$
\frac{\gamma_{O}}{\gamma_{R}}=\eta=\exp \left[\frac{n F}{R T}\left(E-E^{0^{\prime}}\right)\right]
$$


From Eqs. (8) and (11) and, we obtain:

$\exp \left[\frac{n F}{R T}\left(E-E^{0^{\prime}}\right)\right]=\frac{\theta_{O}}{\theta-\theta_{O}} \exp \left[-2 \frac{\phi(\theta)}{\theta}\left(G \theta_{O}+\theta\left(a_{O R}-a_{R R}\right)\right)-2(1-\phi(\theta))\left(a_{O D}-a_{R D}\right)\right]$

$\exp \left[\frac{n F}{R T}\left(E-E^{0^{\prime}}\right)\right]=\frac{\theta_{O}}{\theta-\theta_{O}} \exp \left[-2 \frac{\phi(\theta)}{\theta}\left(G \theta_{O}+\theta\left(a_{O R}-a_{R R}\right)\right)-2(1-\phi(\theta)) D\right]$

with interaction parameters $\left\{\begin{array}{l}G=a_{O O}+a_{R R}-2 a_{O R} \\ S=a_{R R}-a_{O O} . \\ D=a_{O D}-a_{R D}\end{array} \quad\left(a_{O R}=a_{R O}\right)\right.$

In order to extract the i-e characteristic (cyclic voltammetry, $\mathrm{E}=$ $E_{i}+v t$ ), the differentiation of Eq. (13) in $t$ and $\theta_{\mathrm{O}}$ respectively leads to:

$\left(\frac{n F}{R T} v\right) d t=\left(\frac{\theta}{\theta_{0}\left(\theta-\theta_{0}\right)}-2 G \frac{\phi^{n}(\theta)}{\theta}\right) d \theta_{O}$

From Eqs. (10) and (14), the current can be expressed:

$i\left(\theta_{O}\right)=\frac{n^{2} F^{2} A v \Gamma_{\max }}{R T} \frac{\theta \theta_{O}\left(\theta-\theta_{O}\right)}{\theta_{T}^{2}-2 G \theta_{O} \phi(\theta)\left(\theta-\theta_{O}\right)}$

From Eqs. (13) and (15), peak potential $\left(E_{p}\right)$ and peak current $\left(i_{p}\right)$ can be extracted for $\theta_{\mathrm{O}}=\theta / 2$.

$E_{p}(\phi(\theta))=E^{0^{\prime}}+\frac{R T}{n F} S \phi(\theta)-2 \frac{R T}{n F}(1-\phi(\theta)) D$

$i_{p}(\phi(\theta), \theta)=\frac{n^{2} F^{2} v A \Gamma_{\max }}{R T} \frac{\theta}{2(2-G \phi(\theta))}$

From Eqs. (13), (15), (16) and (17), full width at half maximum (FWHM) can be extracted for $\mathrm{i}=\mathrm{i}_{\mathrm{p}} / 2$.

$\begin{aligned} \operatorname{FWHM}(\phi(\theta))= & \frac{2 R T}{n F}\left[\ln \left(\frac{1+\sqrt{\frac{G \phi(\theta)-2}{G \phi(\theta)-4}}}{1-\sqrt{\frac{G \phi(\theta)-2}{G \phi(\theta)-4}}}\right)-G \phi(\theta) \sqrt{\frac{G \phi(\theta)-2}{G \phi(\theta)-4}}\right] \\ & \stackrel{|G \phi(\theta)<1|}{\approx} \frac{R T}{n F}\left(2 \ln (2 \sqrt{2}+3)-\frac{3 \sqrt{2}}{2} G \phi(\theta)\right)\end{aligned}$

\subsection{Discussion}

\subsubsection{Differences between the two models}

A comparison between Eqs. (16), (17) and (18) and Eqs. (1), (2) and (3) shows that only the peak potential (Ep) of cyclic voltamograms (CVs) is affected, when the interaction between redox and non-redox species are taken into account.

The difference between Eqs. (1) and (16) is equal to:

$\left|\Delta E_{p}(\theta)\right|=2 \frac{R T}{n F}|D|[1-\phi(\theta)] \quad$ with $|D| \leq 2$

This means that, if the molecules used to dilute a SAM can interact with the redox species, a maximum variation of $103 \mathrm{mV}(\mathrm{T}=298 \mathrm{~K}$, $\mathrm{D}=2$ and $\phi(\theta) \approx \theta \rightarrow 0$ ) on the peak potential can be obtained from the previous model, whatever the distribution is. This extreme variation makes the previous generalized lateral interactions model unusable.

This phenomenon is clearly shown on Fig. 2. The shapes of the CVs are identical whereas the peak potentials are affected by $\mathrm{a}_{\mathrm{OD}}$ when the surface coverage of electroactive molecules decreases.

The determination of $\mathrm{D}$ is not very easy and can be made only if the interaction constants $G$ and $S$ are precisely known (case of a non-interacting diluent). In that case, the value of $\mathrm{D}$ is determined by adjusting the experimental points with Eq. (16).

\subsubsection{Potential applications}

Blanchard et al. [5] provides evidence of electrochemical transduction without a covalent link between redox (ferrocene) and complexant (crown ether) units in mixed SAMs and demonstrates, without giving further explanation, that the electrochemical transduction (i.e. the potential shift) depends on the crown ether/ferrocene ratio (i.e. the surface coverage of ferrocene).

Considering that the crown ethers act as, either a "neutral" diluent (i.e. free) or a diluent which interacts with the redox molecules (i.e. complexed), this unusual result can be interpreted by the lateral interactions model including interactions between redox and non-redox species. The peak potential shift can be expressed as:

$\Delta E_{p}(\theta)=E_{p}($ complexed $)-E_{p}($ free $)=-2 \frac{R T}{n F} D[1-\phi(\theta)]$
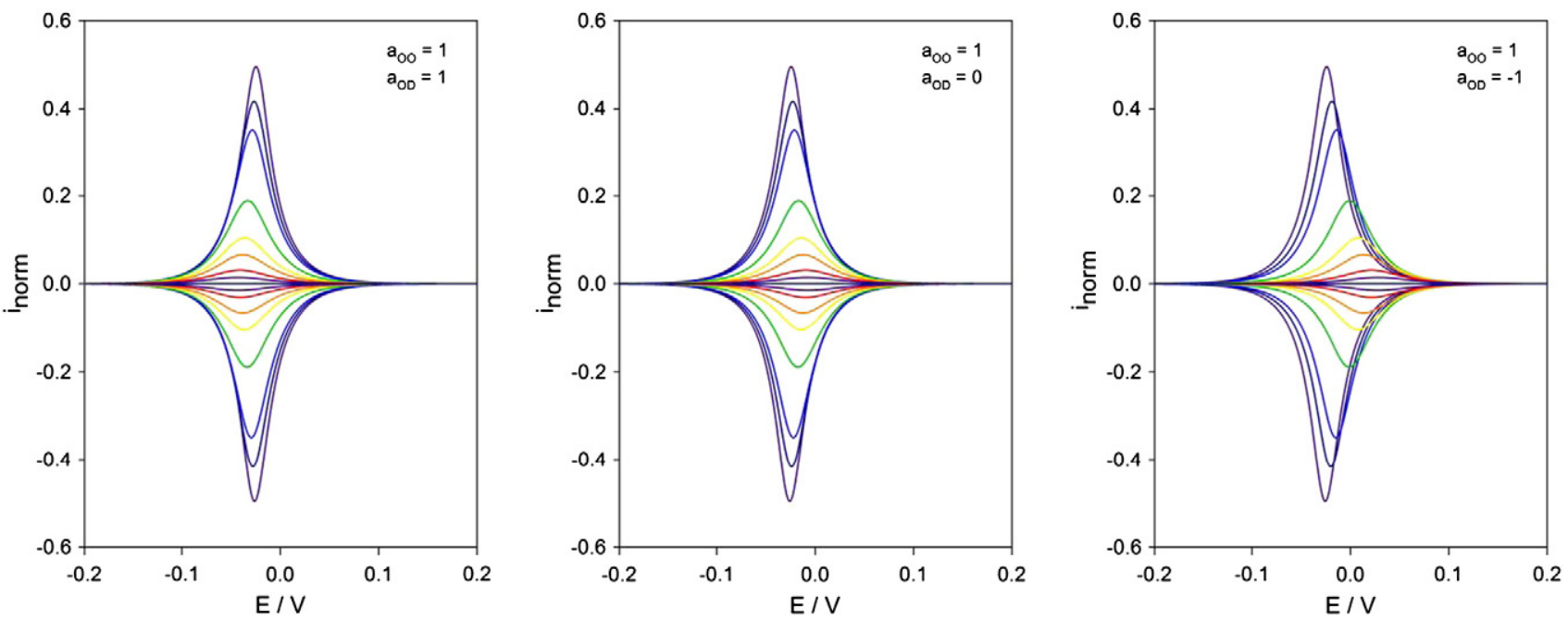

Fig. 2. i-E characteristics of cyclic voltamograms, calculated from Eq. (10), as a function of $\theta=\{1,0.9,0.8,0.5,0.3,0.2,0.1,0.05,0.0001\}$, for a random distribution of electroactive species and for given values of $G=-S=a_{O O}=1$ and $D=a_{O D}=\{-1,0,1\}$. Others parameters: $\mathrm{k}_{\mathrm{s}}=100000 \rightarrow \infty$ (full reversible reaction), $\mathrm{E}^{0^{\prime}}=0 \mathrm{~V}, \mathrm{v}=0.1 \mathrm{~V} . \mathrm{s}^{-1}$ and $\mathrm{T}=293 \mathrm{~K}$. The currents are normalized according to $i_{\text {norm }}=i /\left(n^{2} F^{2} v A F T / R T\right)$ [7]. 


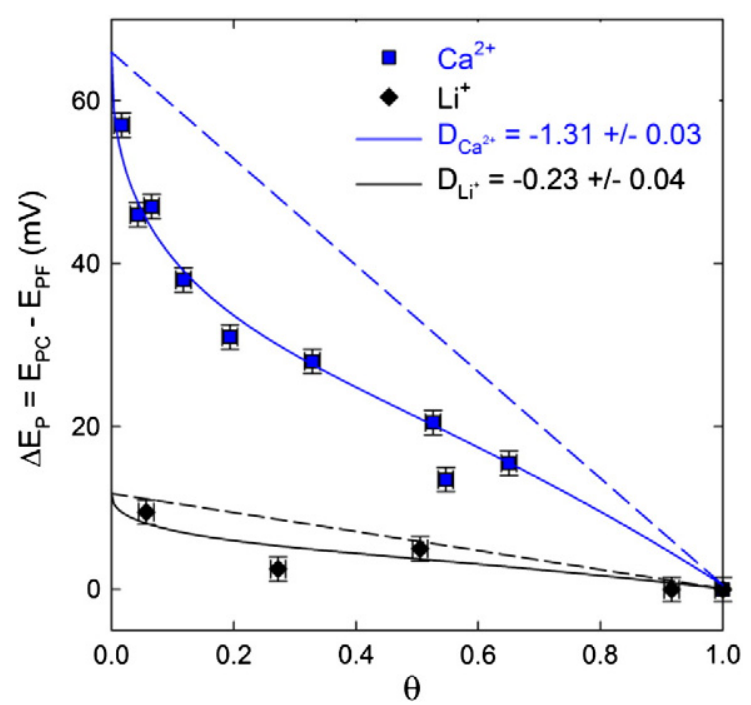

Fig. 3. Peak potentials shift $\left(\Delta \mathrm{E}_{\mathrm{p}}\right)$ before and after complexation with $\mathrm{Ca}^{2+}$ (Blue square) and $\mathrm{Li}^{+}$(Black diamond), as a function of the surface coverage. (Blue and black lines) Adjustments of experimental data using Eq. (19), with a non-random distribution $\phi(\theta)$ and a parameter $\mathrm{D}$ depending of each cation. (Blue and black dash lines) Variations in the case of a random distribution.

Because potential shifts are not linear in ferrocene surface coverage $(\theta)$, the interaction parameter $D$ was estimated from experimental data with a non-random surface distribution of the electroactive centers. Fig. 3 compares model outputs (i.e. variation of peak potential before and after complexation from Eq. (20)) with the results of $\mathrm{Ca}^{2+}$ and $\mathrm{Li}^{+}$complexations on mixed SAMs (i.e. borderline cases of the Fig. 3 in reference [5]). As the model predicts, the trend is monotonic, the electrochemical transduction is most effective when redox molecules are highly diluted in the matrix of diluent and a segregation phase of ferrocene sites on mixed SAMs is suggested. In these cases, the peak potential shift can be understood by the establishment of interaction between the oxydized species and complexed crown ether $\left(D=a_{O D}\right)$. By way of reminder, the interaction between cations or anions are possible, because lateral interactions are governed by the interplay of intermolecular forces, electrostatic interactions [13], pairing ions between charged states of redox molecules and electrolytic ions $[14,15]$, and solvatation.

It is important to note that the model matches with the trend observed despite different experimental conditions (quartz crystal microbalance experiments suggest that the crown ether occupies the surface of two ferrocenes, i.e. two cell of the matrix).

\section{Conclusion}

This work updates the lateral interactions model to interactions between redox and non-redox species. Compared with published experimental data, the model seems effective in the case of electrochemical transduction.

\section{Acknowledgments}

This work was supported by the Centre National de la Recherche Scientifique (CNRS-France), the "Agence Nationale de la Recherche" (ANR-France), and the "Région des Pays de la Loire" (France). The authors thank Flavy Alévêque for her critical reading of the manuscript.

\section{References}

[1] R.G. Nuzzo, D.L. Allara, Adsorption of bifunctional organic disulfides on gold surfaces, Journal of the American Chemical Society 105 (1983) 4481-4483.

[2] J.C. Love, L.A. Estroff, J.K. Kriebel, R.G. Nuzzo, G.M. Whitesides, Self-assembled monolayers of thiolates on metals as a form of nanotechnology, Chemical Reviews 105 (2005) 1103-1169.

[3] O. Aleveque, P.Y. Blanchard, C. Gautier, M. Dias, T. Breton, E. Levillain, Electroactive self-assembled monolayers: Laviron's interaction model extended to non-random distribution of redox centers, Electrochemistry Communications 12 (2010) 1462-1466.

[4] E. Laviron, Surface linear potential sweep voltammetry: Equation of the peaks for a reversible reaction when interactions between the adsorbed molecules are taken into account, Journal of Electroanalytical Chemistry and Interfacial Electrochemistry 52 (1974) 395-402.

[5] P.-Y. Blanchard, S. Boisard, M. Dias, T. Breton, C. Gautier, E. Levillain, Electrochemical Transduction on Self-Assembled Monolayers: Are Covalent Links Essential? Langmuir 28 (2012) 12067-12070.

[6] E. Laviron, General expression of the linear potential sweep voltammogram in the case of diffusionless electrochemical systems, Journal of Electroanalytical Chemistry and Interfacial Electrochemistry 101 (1979) 19-28.

[7] E. Laviron, L. Roullier, General expression of the linear potential sweep voltammogram for a surface redox reaction with interactions between the adsorbed molecules: Applications to modified electrodes, Journal of Electroanalytical Chemistry and Interfacial Electrochemistry 115 (1980) 65-74.

[8] O. Aleveque, C. Gautier, M. Dias, T. Breton, E. Levillain, Phase segregation on electroactive self-assembled monolayers: a numerical approach for describing lateral interactions between redox centers, Physical Chemistry Chemical Physics 12 (2010) 12584-12590.

[9] A.J. Bard, L.R. Faulkner, Electrochemical methods: fundamentals and applications, Wiley India Pvt. Ltd., 2006

[10] J.O.M. Bockris, A.K.N. Reddy, Modern electrochemistry, Plenum Press, 2000.

[11] W.L. Bragg, E.J. Williams, The Effect of Thermal Agitation on Atomic Arrangement in Alloys, Proceedings of the Royal Society of London. Series A 145 (1934) 699-730.

[12] S. Andrieu, P. Müller, Les surfaces solides: concepts et méthodes, EDP Sciences, 2005.

[13] C.P. Smith, H.S. Dwhite, Theory of the interfacial potential distribution and reversible voltammetric response of electrodes coated with electroactive molecular films, Analytical Chemistry 64 (1992) 2398-2405.

[14] M. Ohtani, S. Kuwabata, H. Yoneyama, Voltammetric Response Accompanied by Inclusion of Ion Pairs and Triple Ion Formation of Electrodes Coated with an Electroactive Monolayer Film, Analytical Chemistry 69 (1997) 1045-1053.

[15] C. Gautier, O. Aleveque, F. Seladji, M. Dias, T. Breton, E. Levillain, Nitroxyl radical self assembled monolayers: Ion pairing investigation in organic and aqueous media, Electrochemistry Communications 12 (2010) 79-82. 